\title{
MEDIOS IMPUGNATORIOS ORDINARIOS SIN EFECTO DEVOLUTIVO: EL REMEDIO Y EL RECURSO DE REPOSICIÓN
}

\author{
Beatriz Franciskovic Ingunza ${ }^{1}$
}

\section{RESUMEN}

Por medio del presente artículo se analiza a dos medios impugnatorios ordinarios sin efecto devolutivo como lo son el remedio y la reposición. Medios impugnatorios que nuestro ordenamiento jurídico procesal los regula de manera diferenciada, pues considera a la reposición como un recurso (recurso de reposición) y no como un remedio. Por otro lado, cataloga como un remedio a la oposición, cuando en el mismo código procesal civil lo regula dentro de las cuestiones probatorias, como la tacha.

Esta diferencia se ampara en el hecho que nuestro ordenamiento jurídico diferencia a los remedios en base a lo qué es lo que se cuestiona (vicios u errores contenidos o no en una resolución judicial) y no en sus efectos (con efecto o sin efecto devolutivo).

\section{ABSTRACT}

This paper analyzes two common types of non-devolutive remedies: appeal and remedy of reestablishment. These types of remedies are regulated separately in our procedural legal system. The remedy of reestablishment is considered a remedy and not an appeal. On the other hand, it classifies opposition as a remedy, where the code of civil procedures includes such remedy in the section on evidentiary issues, as a strike off.

This difference is due to the fact that our legal system distinguishes remedies in terms of what they are questioning (defects or mistakes included or not in a court decision), and not in terms of their effects (devolutive or non-devolutive).

\section{PALABRAS CLAVES}

Instancia plural - doble instancia - medio impugnatorio - medio impugnatorio con efecto y sin efecto devolutivo cuestiones probatorias- tacha - oposición - remedio - recurso - reposición

\section{KEYWORDS:}

Multiple Level Court System - Right of Appeal - Remedies- Devolutive or Non-Devolutive Remedy - Evidentiary Issues - Strike Off - Opposition - Remedy - Appeal - Reestablishment

1 Abogada. Árbitro adscrito a varias instituciones arbitrales. Docente de la Facultad de Derecho de la Universidad Ricardo Palma. Científica del Sur, y UNIFé. Abogada del Instituto Vida, Salud y Gestión S.C. L. 


\section{INTRODUCCIÓN}

Nuestro actual Código Procesal Civil se encuentra vigente desde el 28 de julio de 1993, el mismo que carece de una exposición de motivos hasta la actualidad, sin embargo, no cabe duda que éste cuerpo normativo procesal contempla algunas figuras jurídicas, como el remedio y el recurso de reposición, los mismos que no han sido totalmente estudiados, resultan inaplicables a nuestra realidad. Al referirnos a los medios impugnatorios ordinarios con efecto o sin efecto devolutivo tenemos que abarcar lo concerniente al principio de la doble instancia o pluralidad de instancia consagrado en nuestra Constitución Política (artículo $139^{\circ}$ inciso 6) como en el artículo $X$ del Título preliminar del Código Procesal Civil, qué significa impugnar, clases de medios impugnatorios que nuestro código procesal regula así como desarrollar el tema relativo al remedio y al recurso de reposición.

\section{El PRINCIPIO DE PLURA- LIDAD DE INSTANCIA O DOBLE INSTANCIA}

Este principio constitucional se refiere al Derecho a la impugnación, el mismo que forma parte consustancial del Derecho al Debido Proceso. Constituye un derecho fundamental y un principio de la administración de justicia que se encuentra regulado en el inciso $6^{\circ}$ del artículo $139^{\circ}$ de nuestra Constitución Políti$c a, y$ a nivel infra constitucional en el artículo $X$ del Título Preliminar del Código Procesal Civil.
Según, Landa Arroto, Cesar “El derecho a la pluralidad de instancias tiene como finalidad garantizar que lo resuelto por un órgano jurisdiccional pueda ser revisado en instancias superiores a través de los correspondientes medios impugnatorios formulados dentro del plazo legal“(Landa Arroyo, 2012, pág. 35).

"El reconocimiento de este principio y derecho garantiza que todo lo efectuado $\mathrm{y}$, o resuelto por un órgano jurisdiccional pueda ser revisado, bien por el mismo órgano judicial que expidió el acto procesal, o por un órgano de mayor jerarquía. El fundamento de este principio se basa en la probabilidad de que el Juez, es un ser humano y como tal puede incurrir o cometer un error de apreciación de los hechos y el derecho, un error de aplicación y, o interpretación de una norma jurídica así como un error material o formal en la actuación de un acto procesal.“ (Franciskovic Ingunza , 2015, pág. 107).

Juan Monroy Gálvez, sostiene que el derecho a la impugnación es el "instrumento que la ley concede a las partes o a terceros legitimados para que soliciten al juez que, el mismo u otro de jerarquía superior, realicen un nuevo examen de un acto procesal o de todo el proceso, a fin de que se anule o revoque, total o parcialmente" (Monroy Gálvez, 2003, pág. 196).

Una correcta y debida aplicación de este principio significa que a ningún sujeto de derecho se le puede vulnerar o prohibir el poder ejercitar su derecho a la impugnación.

\section{QUÉ SE ENTIENDE POR IM- PUGNAR}

Según el Diccionario de la Real Academia de la Lengua Española impugnar significa "combatir, contradecir, refutar”.

Es decir, impugnar un acto jurídico procesal o una resolución judicial, significa contradecir, rebatir o cuestionar dicho acto o conducta procesal por contener o estar plagada de algún vicio o error, con el único fin que dicha conducta o acto procesal sea revisado $y$, de ser el caso, dicho acto o conducta sea confirmado, revocado o sea declarado nulo, total o parcialmente.

“Jurídicamente -y más específicamente, dentro del ámbito procesal-dicho término supone cuestionar o contradecir un determinado acto jurídico procesal expedido por un órgano jurisdiccional denunciando que el acto cuestionado ha incurrido en un error. De esta manera, el error se convierte en el fundamento de la impugnación procesal, pues lo que se desea con el instituto de la impugnación procesal es precisamente concederle a las partes la posibilidad de impugnar un acto denunciando un error con la finalidad de que éste sea corregido" (Priori Posada, 2002, pág. 221).

La impugnación supone, "de manera general, cuestionar un determinado acto denunciando un error, a fin que ésta sea corregido. [...] El esquema de toda impugnación procesal será el siguiente: i) La existencia de un error, ii) la denuncia del error, y iii) la corrección del error." (Apolin Meza , 2010, pág. 53). 
El derecho a la impugnación consiste en aquella facultad o poder que el ordenamiento jurídico concede a todo sujeto de derecho de poder impugnar, cuestionar o contradecir un acto jurídico procesal emitido por un órgano jurisdiccional por estar contaminado con vicios o errores procesales, con el propósito que dicho acto procesal sea revisado $\mathrm{y}, \mathrm{o}$ corregido por el órgano superior.

Es así que el Juez revisor no puede por pereza o por otras causas aplazar el tiempo en el desarrollo del proceso.

\section{NOCIÓN DE MEDIOS IM- PUGNATORIO Y CLASES DE MEDIOS IMPUGNATORIOS}

Según Véscovi, se trata de previsiones sanatorias o correctivas. Cuando las partes dirigen su actividad en procura de la corrección o eliminación jurisdiccional del posible defecto o injusticia del acto cumplido hacen valer un poder de impugnación. Ese poder emana del derecho de acción. Se trata de un derecho abstracto, que no está condicionado a la existencia real del defecto o la injusticia. No interesa que quien recurre tenga un derecho concreto; basta que invoque su poder para que se le permita ejercer la actividad impugnativa, aunque luego, como sucede con la acción, se le deniegue el derecho (Vescovi, 1988, pág. 33).

Los medios impugnatorios se dividen en medios impugnatorios ordinarios y medios impugnatorios extraordinarios.

i) Los medios impugnatorios ordinarios son aquellos que se pueden plantear e interponer dentro del trámite de un proceso judicial, por contener un vicio o error que se encuentra contenido o no en una resolución judicial.

ii) Los medios impugnatorios extraordinarios, por el contrario, son aquellos que solo se pueden entablar una vez concluido el proceso judicial, a través de la interposición de una demanda cuya pretensión sea la de solicitar la nulidad de cosa juzgada fraudulenta o a través del proceso constitucional de amparo.

iii) Los medios impugnatorios ordinarios, a su vez, se dividen en: - medios impugnatorios ordinarios con efecto devolutivo y medios impugnatorios ordinarios sin efecto devolutivo.

a. 1). Los medios impugnatorios ordinarios con efecto devolutivo se refieren a aquellos medios que se interponen ante el Juez que expidió el acto procesal con el fin que el Superior Jerárquico sea quien revise y, o corrija el vicio o error contenido en una resolución judicial (decreto, auto o sentencia). Dentro de los medios impugnatorios con efecto devolutivo encontramos a los recursos impugnatorios.

a. 2). Los medios impugnatorios ordinarios sin efecto devolutivo se refieren a aquellos medios que se interponen ante el mismo Juez que expidió el acto procesal, para que sea el mismo Juez, actor o ejecutor de un acto jurí- dico procesal, quien revise dicho acto procesal, y en consecuencia, proceda, de ser el caso, a corregirlo declarándolo nulo, total o parcialmente, o revocando dicho acto jurídico procesal. Dentro de los medios impugnatorios ordinarios sin efecto devolutivo encontramos a los remedios procesales.

"Dentro de la impugnación en sentido estricto debe distinguirse entre remedios y recursos; en el primer caso la impugnación no tiene efecto devolutivo, por lo que conocerá de ella el mismo órgano judicial que dictó la resolución que se impugna; en los recursos por el contrario, el efecto devolutivo pertenece a su esencia, conociendo de ellos un órgano distinto y superior al que dictó la resolución que se impugna, con lo que aparece la distinción entre órgano inferior (iudex a quo) y órgano superior (iudex ad quem)" (Montero Aroca , 2005 , pág. 721).

\section{EL REMEDIO Y EL RECUR- SO DE REPOSICIÓN}

Nuestro Código Procesal Civil específicamente en el artículo $356^{\circ}$ distingue a los recursos de los remedios.

Según lo dispone dicho artículo, "los remedios pueden formularse por quien se considere agraviado por actos procesales no contenidos en resoluciones. La oposición y los demás remedios sólo se interponen en los casos expresamente previstos en este Código y dentro de tercer día de conocido el 
agravio, salvo disposición legal distinta". Mientras que los recursos pueden formularse por quien se considere agraviado con una resolución o parte de ella, para que luego de un examen de ésta, se subsane el vicio o error alegado"

\subsection{Los remedios}

Constituyen un medio impugnatorio ordinario sin efecto devolutivo. Se cuestiona un vicio $u$ error que no se encuentre contenido en una resolución judicial.

"Son aquellos medios impugnatorios encaminados a lograr que se anule o revoque, ya sea en manera parcial o total determinados actos procesales que no se encuentran contenidos en resoluciones. Se interpone ante el mismo juez que conoció el acto procesal materia de impugnación. Así los remedios pueden ser dirigidos contra el acto de notificación, la actuación de un medio de prueba, una diligencia externa realizada por el secretario, etc, es decir, cualquier acto procesal que no se encuentre comprendidos en una resolución” (Rioja Bermudez , 2014, pág. 1033).

"Los remedios con medios impugnatorios dirigidos a que se anule o se revoque o reste eficacia, ya sea en forma parcial o total, a actos procesales que no se encuentran contenidos en resoluciones, Así, a través de los remedios es posible impugnar el acto de notificación, oponerse a la actuación de un medio de prueba (Hinostroza Minguez, 2003, pág. 648).

Dentro de los remedios, (primer párrafo del artículo $356^{\circ}$ del código procesal civil) se señala a la oposición y a los demás remedios (sin señalar cuáles son) el cual se interpone en los casos expresamente previstos por éste código y dentro de tercer día de conocido el agravio.

Siguiendo a Rioja Bermúdez, las clases de remedios son la oposición, la tacha y la nulidad. (Rioja Bermudez , 2014, pág. 1034).

Al respecto es importante precisar que la oposición se encuentra regulada, al igual que la tacha, en el artículo 300 y ss. del citado código. Constituyen cuestiones probatorias que tienen por finalidad cuestionar (interponer tacha y, u oposición) los medios probatorios ofrecidos por las partes del proceso.

La tacha y la oposición solo puede ser interpuesta por las partes del proceso, dentro de los plazos establecidos en cada vía procedimental. Por la tacha se cuestiona por falsa o nula una declaración de testigos, los documentos o pruebas atípicas para que estas no sean incorporadas al proceso. Mientras que por la oposición se busca que la declaración de parte, una exhibición, una pericia, inspección judicial o medio probatorio atípico pierdan eficacia y no se actúen oportunamente.

Considero que la oposición y la tacha no pueden ser consideradas como remedios procesales, punto que será explicado posteriormente.

\subsection{El recurso de reposición}

Se interpone ante el juez que emitió dicha resolución. No tiene efecto devolutivo. $\mathrm{El}$ juez que emitió el decreto será el que resolveré el recurso.

Es un medio de impugnación que busca obtener del mismo órgano e instancia que dictó la resolución, la subsanación de los agravios que aquella pudo haber inferido. [...] lo fundamental en este tipo de recursos es que la revocatoria se obtenga en la misma instancia donde la resolución fue emiti$\mathrm{da}$, al margen que la revocatoria provenga de un juez o de un colegiado. (Ledesma Narváez , 2009 , pág. 748).

Constituye un medio impugnatorio ordinario sin efecto devolutivo. Es decir, ni el expediente ni la resolución impugnada son elevados al superior jerárquico para que lo revise. Es el mismo juez que expidió la resolución -el decreto- quien resolverá sobre el recurso presentado.

El recurso de reposición procede únicamente contra los decretos. El decreto es una resolución de menor trascendencia, de mero trámite y que sirve para impulsar el proceso. "mediante los decretos se impulsa el desarrollo del proceso, disponiendo actos procesales de simple trámite. Se caracterizan, por la simplicidad de su contenido y la carencia de motivación. Son expedidos por los auxiliares jurisdiccionales, siendo suscritos con sus firma completa, salvo aquellos que se expidan por el juez dentro de las audiencias" (Hinostroza Minguez, 2003, pág. 661).

No cabe duda que la reposición constituye una excepción a los recursos que tienen efecto devolutivo. Por ello, considero que nuestro ordena- 
miento jurídico procesal civil debe diferenciar a los medios impugnatorios ordinarios en devolutivos y no devolutivos y no en recursos y remedios; y dentro de los no devolutivos ubicar al remedio y a la reposición. Excluyéndose de los recursos a la reposición.

El trámite del recurso de reposición: Una vez presentado el recurso, el juez lo admite, lo declara inadmisible o improcedente. Si lo admite puede conferir traslado a la otra parte para que dentro del plazo de tres días absuelva lo conveniente, con su absolución o sin ella, el juez resolverá sin necesidad de más trámite. Si lo declara inadmisible concede un plazo para que dicho vicio u error de forma sea subsanado y de ser subsanado, lo admitirá, si advierte errores insubsanables lo declarará improcedente sin más trámite.

Si el decreto es expedido en una audiencia, el recurso de reposición debe ser interpuesto oralmente, se corre traslado a la otra parte y con su absolución o sin ella, el juez resolverá.

Una vez admitido el recurso de reposición el juez lo resolverá mediante un auto. Dicho auto es inimpugnable.

\section{SEMEJANZAS Y DIFERENCIAS ENTRE EL REMEDIO Y EL RECURSO DE REPOSICIÓN}

Semejanzas: Ambos constituyen medios impugnatorios ordinarios sin efecto devolutivo que se interponen con el fin que sean revisados por el mismo juez que emitió el acto o por el superior jerárquico para que corrija, confirme o revoco lo ahí consignado.
Diferencias: Quien se considere agraviado por un acto procesal no contenido en una resolución judicial puede hacer uso del remedio impugnatorio, mientras que quien se considere agraviado con una resolución judicial puede interponer un recurso impugnatorio.

Dentro de los remedios, nuestro ordenamiento jurídico procesal civil, señala a la oposición y a los demás remedios (sin señalar cuáles son) el cual se interpone en los casos expresamente previstos por éste código y dentro de tercer día de conocido el agravio; mientras que dentro de los recursos se ubica al recurso de reposición (artículo $362^{\circ}$ y ss.), al recurso de apelación (artículo $364^{\circ}$ y siguientes), al de casación (artículo $384^{\circ}$ y ss.) y al recurso de queja (artículo $401^{\circ}$ y siguientes), los cuales se interponen contra decretos (el de reposición), contra autos, autos que pongan fin a la instancia y sentencias (el de apelación) contra resoluciones de vista (recurso de casación) y el de queja (cuando no se conceda la apelación o se conceda en efecto distinto al solicitado).

De lo descrito resulta importante hacer tres precisiones, i) respecto a la diferencia entre remedios y recursos, ii) respecto a los remedios $\mathrm{y}$, iii) respecto al recurso de reposición.

\section{i) Respecto a la diferencia entre los remedios y re- cursos}

Nuestro código procesal civil distingue a los remedios de los recursos teniendo en cuenta qué es lo que se cuestiona o contradice (un acto procesal contenido o no en una resolución), sin precisar cuáles son los remedios únicamente señalando a la oposición como un remedio cuando no lo es. (Esto se explicará líneas siguientes en el punto ii)

Soy de la opinión que la diferencia o distinción entre el remedio y los recursos debió tener en cuenta si estas tienen o no efecto devolutivo, así los remedios serían los medios impugnatorios sin efecto devolutivo mientras que los recursos serían los medios impugnatorios con efecto devolutivo. Dentro de los remedios se ubicaría al remedio y a la reposición y dentro de los recursos a de apelación, casación y queja.

\section{ii) En cuanto a los remedios}

Dentro de los remedios, nuestro ordenamiento jurídico procesal civil, señala a la oposición y a los demás remedios, sin señalar expresamente cuáles son.

Considero que la oposición y la tacha no pueden ser considerados como remedios procesales, es decir, no deben ser considerados como medios impugnatorios ordinarios sin efecto devolutivo- en base a las siguientes razones:

ii.a) La tacha y la oposición se encuentran textualmente reguladas como cuestiones probatorias en el artículo $300^{\circ}$ y ss. del código procesal civil,

ii.b) La tacha y la oposición tienen por finalidad cuestionar a los medios probatorios ofrecidos por las partes para que estos se invaliden o pierdan 
eficacia probatoria. El ofrecimiento de los medios probatorios constituye una manifestación del derecho al debido proceso -derecho a la prueba- de las partes del proceso. Mientras que la finalidad de los medios impugnatorios ordinarios (remedios o recursos) es cuestionar algún vicio u error contenido o no en una resolución judicial.

ii.c) Se tacha un medio probatorio por nulo o falso para que no se incorpore al proceso y, o se opone a la actuación de un medio probatorio para que no se actúe oportunamente. En cambio se cuestiona un acto procesal contenido o no en una resolución judicial por causar algún agravio o perjuicio.

ii. d) La tacha y la oposición solo puede ser interpuesta por las partes del proceso (demandante o demandado), mientras que los medios impugnatorios (remedios y recursos) puede ser interpuesta por las partes o terceros legitimados.

ii.e) La oposición y la tacha no se interponen específicamente dentro de los tres días de conocido el agravio, si no que dependiendo de cada vía procedimental se interponen a los cinco días en el proceso de conocimiento, a los tres días en el abreviado y a los cinco días en el sumarísimo, conjuntamente con la contestación de la demanda.

\section{iii) En cuanto al recurso de reposición}

Reitero que este no debe establecerse como un recurso sino como un remedio, pues, la reposición solo procede contra decretos y estos no tienen efecto devolutivo como si lo tiene el recurso de apelación, casación y queja.

\section{CONCLUSIONES}

- Impugnar un acto jurídico procesal o una resolución judicial, significa contradecir o cuestionar dicho acto - conducta procesal por contener o estar plagada de algún vicio o error, con el único fin que dicha conducta o acto procesal sea revisado y, de ser el caso sea confirmado, revocado o que sea declarado total o parcialmente nulo.

- Los medios impugnatorios se dividen en medios impugnatorios ordinarios $y$ medios impugnatorios extraordinarios.

Los medios impugnatorios ordinarios, a su vez, se dividen en: - medios impugnatorios ordinarios con efecto devolutivo y medios impugnatorios ordinarios sin efecto devolutivo.

- Nuestro Código Procesal Civil, específicamente en el artículo $356^{\circ}$ distingue a los recursos de los remedios.

- El remedio constituye un medio impugnatorio ordinario sin efecto devolutivo. Se cuestiona un vicio u error que no se encuentre contenido en una resolución judicial.

- La oposición se encuentra regulada, al igual que la tacha, en el artículo 300 y ss. del citado código. Constituyen cuestiones probatorias que tienen por finalidad cuestionar (interponer ta- cha y, u oposición) los medios probatorios ofrecidos por las partes del proceso.

- Considero que la oposición y la tacha no pueden ser consideradas como remedios procesales.

El recurso de reposición se interpone ante el juez que emitió dicha resolución. No tiene efecto devolutivo. El juez que emitió el decreto será el que resolveré el recurso. Es decir, ni el expediente ni la resolución impugnada son elevados al superior jerárquico para que lo revise. Es el mismo juez que expidió la resolución -el decreto- quien resolverá sobre el recurso presentado.

- No cabe duda que la reposición constituye una excepción a los recursos que tienen efecto devolutivo. Por ello, considero que nuestro ordenamiento jurídico procesal civil debe diferenciar a los medios impugnatorios ordinarios en devolutivos y no devolutivos y no en recursos y remedios; y dentro de los no devolutivos ubicar al remedio y a la reposición. Excluyéndose de los recursos a la reposición.

\section{BIBLIOGRAFÍA}

Apolin Meza, D. (2010). Impugnación y adecuación: Sobre la mal considerada inimpugnabilidad del auto admisorio. Lima: Themis.

Franciskovic Ingunza, B. A. (2015). El remedio como medio impugnatorio ordinario sin efecto devolutivo. Lima: Actualidad Civil. 
Nro.12. Junio 2015(12), Ledesma Narváez, M. (2009). 304-313.

Hinostroza Minguez, A. (2003). Comentarios al Código Procesal Civil. Análisis artículo por artículo. (Vol. I). Lima: Gaceta Jurídica.

Landa Arroyo, C. (2012). El Derecho al debido proceso en la Jurisprudencia: Corte Suprema de Justicia de la República del Perú, Tribunal Constitucional del Perú, Corte Interamericana de Derechos Humanos. Colección cuadernos de análisis de la Jurisprudencia. V, 35.
Comentarios al Código Procesal civil. Análisis artículo por artículo. Lima : Gaceta Jurídica .

Monroy Gálvez, J. (2003). Los medios impugnatorios en el Código Procesal Civil. La Formación del proceso Civil Peruano. Escritos Reunidos.

Montero Aroca , J. (2005). Tratado de Recursos en el Proceso Civil. Valencia : Tirant Lo Blanch.

Priori Posada, G. (2002). Comentarios a la Ley del
Proceso Contencioso Administrativo (Segunda ed.). Lima: Ara Editores.

Rioja Bermudez, A. (2014). Teoría General. Doctrina. Jurisprudencia. Lima: Adrus editores.

Solé Riera , J. (1998). El recurso de apelación. Barcelona: J.M. Bosch Editor.

Vescovi, E. (1988). Los recursos judiciales y demás medios impugnativos en iberoamérica.. Buenos Aires : Depalma. 
